American Journal of Applied Sciences 6 (3): 463-470, 2009

ISSN 1546-9239

(C) 2009 Science Publications

\title{
How Does The Bone Shaft Geometry Affect its Bending Properties?
}

\author{
${ }^{1}$ Kaveh PourAkbar Saffar, ${ }^{2}$ Nima JamilPour and ${ }^{1}$ Seyed Mohammad Rajaai \\ ${ }^{1}$ Department of Mechanical Engineering, \\ Iran University of Science and Technology, Tehran, Iran \\ ${ }^{2}$ School of Engineering, Semnan University, Semnan, Iran
}

\begin{abstract}
In this research, ten fresh specimens of sheep tibiae were provided from slaughtered animals. Whole bone specimens were loaded in three-point bending according to standard wet bone test protocols. Mechanical properties were determined and compared with the results which were obtained from two dry bone tests. The results showed that fracture bending moment and bone extrinsic stiffness had significant relations with fracture cross-section dependent parameters (i.e., cross-section area and area moment of inertia). Where, fracture energy and ultimate strength did not have such a relation with these parameters. Finite element modeling of bone shaft was made with simplified geometry (neglecting cross-section variations along bone shaft) in two steps: First, by elliptical crosssection and second, by circular cross-section, assuming linear elastic and isotropic properties for the specimens. Elastic (Young's) modulus and fracture load, evaluated from curves obtained from tests, were applied to the finite element model and close results of maximum stress in both test specimen and first (elliptical cross-section) model showed up. There was an average difference of about $2 \%$ between ultimate strength of wet bone specimens and maximum (tensile) stress occurred in the elliptical models. However, this value for circular models was about $16 \%$.
\end{abstract}

Key words: Bone mechanical properties, bone geometry, three-point bending, finite element modeling

\section{INTRODUCTION}

Bone undergoes complex patterns of loading during lifetime. External and internal forces act to deform the bone. Prediction of bone behavior under applied loads necessitates having recognition about its mechanical properties. Mechanical testing of bone is a common way to determine its properties ${ }^{[1]}$. In some studies, compact or spongy bone is machined and tested with desired geometry ${ }^{[2-4]}$. But, there is a risk of damage or mutation in bone tissue, caused by high temperatures due to machining process, which may affect the results. Moreover, bone has an anisotropic structure and its structural properties vary with load direction ${ }^{[4]}$. Bone materials properties depend upon its mineral contents densities and collagenous contents ${ }^{[5]}$. It is thought that, while performing tests, related materials and geometric dimensions affect the bone strength (in flexion, torsion or compression), depending on load type and direction applied on the whole bone ${ }^{[6,7]}$. Therefore, frequent testing methods for other materials can not determine the bone structural characteristics ${ }^{[6,7]}$ and, testing whole bone may be another way to study its properties.
Bone strength and elastic modulus are functions of load applying direction and are stronger in compression comparing to tension. These varieties could be due to orthotropic properties of bone that cause its strength and modulus to be a function of tissue orientation exposed to $\operatorname{load}^{[7,8]}$. In addition, wet and dry bone specimens demonstrate different characteristics during tests $^{[8]}$.

Usually, three-point and four-point bending and torsion tests are used to determine whole bone mechanical strength. Three-point bending test has commonly been used in the evaluation of bone strength in earlier studies, which have shown that bending breaking force (breaking or fracture load) and stiffness, as well as the intrinsic parameters, ultimate stress (breaking strength) and elastic modulus are good indicators of the mechanical strength of cortical bone ${ }^{[9]}$.

In this study, the procedure and results of performing three-point bending test of sheep tibia are discussed. Using a simple finite element model, by considering two possible approximations for bone shaft cross-section, it is shown that bone shaft strength is optimally enhanced by its geometry. It is also demonstrated that the variations of long bone specimen

Corresponding Author: Kaveh PourAkbar Saffar, Department of Mechanical Engineering,Iran University of Science and Technology, Tehran, Iran Tel: +98-912-3763761 Fax: +98-21-77721534 
geometry along its shaft did not significantly affect bending strength of whole bone.

\section{MATERIALS AND METHODS}

Test specimens can be chosen from animal models, such as rabbits, dogs, pigs and sheep ${ }^{[10]}$. Sheep are a promising model for various reasons. They are docile, easy to handle and house, relatively inexpensive, available in large numbers and spontaneously ovulate. Sheep have hormone profiles similar to women and some bone structures similar to human ${ }^{[11]}$.

Twelve sheep tibiae were chosen (ten, for wet tests and the other two, for dry tests). It was necessary to ream the bone specimens from the corpses immediately after slaughtering, to provide wet conditions, for minimizing the changes of bone in-vitro properties. Thus, they were to be taken from slaughter-house. Some factors were considered before slaughtering to diminish probable faults in results, such as sex, color and race. All specimens were chosen from left tibiae of cream-colored female sheep of a same herd of Kurdish race, in weight range of $52-65 \mathrm{Kg}$. Homomorphic breeding and similar nutrition are the cases accomplished in a same herd that can play an important role in diminishing faults.

Immediately after slaughtering, the ten fresh specimens were reamed from corpses, cleaned and sank in physiologic saline 0.009 and kept at $4^{\circ} \mathrm{C}^{[8,12]}$. Fresh bone specimens were tested after less than $24 \mathrm{~h}$. For longer intervals, the specimens should be frozen at $-20^{\circ} \mathrm{C}$ in saline soaked gauze and thawed at room temperature just before testing ${ }^{[8,9,12]}$. The other two specimens were preserved in refrigerator, for dry tests.

Bending can be applied to bone using either threepoint or four-point bending. The advantage of threepoint bending is its simplicity, but it has the disadvantage of creating high shear stress near the midsection of the bone. Four-point loading produces pure bending between the two loading points, which ensures that transverse shear stresses are zero. However, four-point bending requires that the force at each loading point be equal. This requirement is simple to achieve in regularly shaped specimens but difficult to achieve in whole bone tests ${ }^{[1,10]}$. Therefore, three-point bending is used more often for measuring the mechanical properties of long bones.

Bending test accuracy will decrease if the bone is not straight enough. Sheep tibia was chosen because of its relatively regular shape and spare curvature. For example, sheep femur has a shorter length and a considerable lateral curvature that may affect threepoint bending test results.

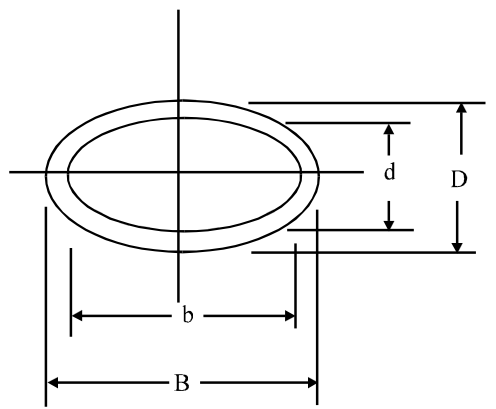

Fig. 1: Assumed elliptical cross-section of sheep tibia shaft

According to standard testing method, published by American Society of Agricultural Engineers, for threepoint bending test of animal bone, some cases should be considered: Three-point bending test should be used only when the bone is straight, has a symmetrical crosssection and has a support length to diameter ratio greater than 10. Testing machine should be capable of applying constant rate of crosshead movement with reproducible speed and accuracy of $\pm 1.0 \%$. Three-point bending test fixture with adjustable fulcra should be used in order to obtain a support length to bone diameter ratio greater than 10 . Details and previous histories about the animals from which the bones were taken also should be recorded.

Although fresh specimens were kept under wet conditions in contrast to dry specimens, both wet and dry tests followed the same procedure during mechanical testing.

Three-point bending tests: The sheep tibia shaft was assumed to be a hollow shaft with an elliptical crosssection (Fig. 1), as it could be an acceptable assumption according to Fig. 2. The substance of compact bone was considered to be homogeneous and have linear elastic properties.

Zwick/Roell $321 \mathrm{htm} 123$ testing machine, in Biomaterials Physical-Mechanical Properties Lab., Department of Biomedical Engineering, Amirkabir University of Technology, was used. Loading capacity of the apparatus was 2.5 tons.

Specimens were propped up horizontally in the apparatus with flattest side down and anterior surface upwards, centered on the supports. The two support points were rounded to avoid shear load and cutting ${ }^{[9]}$. Fulcra spam length was adjusted to the active length of each bone shaft and the load point was set on the middle of this length. At this point, the exterior dimensions of the cross-section were measured using a vernier. While applying load with a rate of 

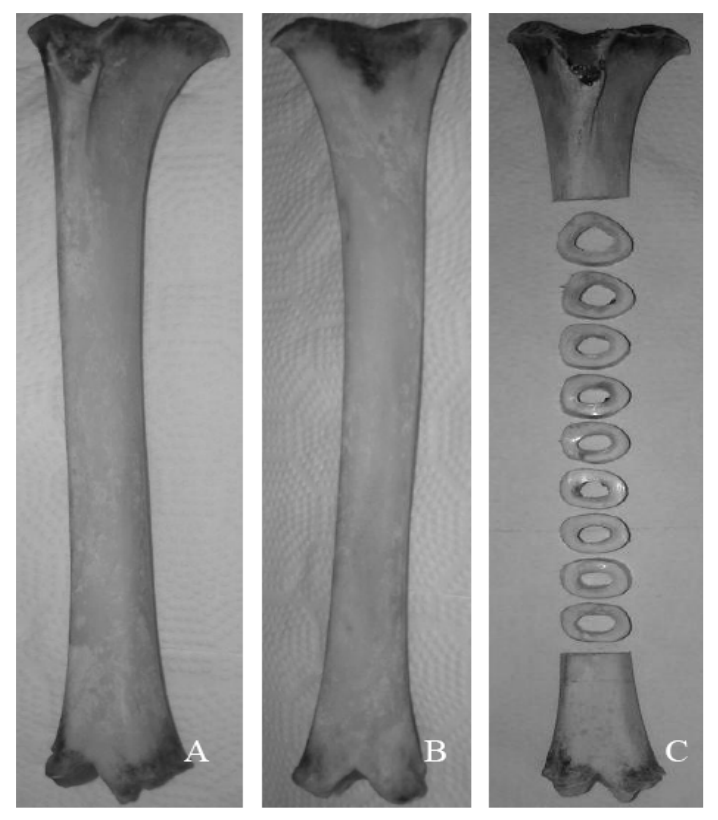

Fig. 2: (A, B): Anterior and posterior views of sheep tibia, (C): Variations of cross-section and its similarity to ellipse along the bone shaft

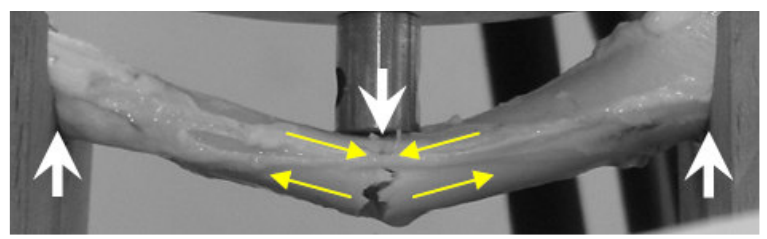

Fig. 3: Fracture instant of a specimen. Tension in lower side and compression in upper side

$10 \mathrm{~mm} / \mathrm{min}$, the machine drew out force-deformation curves. Deformation is the amount specimen deflects under load. Interior dimensions were measured after fracture occurred. Thus, initial and raw data were obtained. Figure 3 shows the fracture instant of a specimen.

Bending equations for bone: Using beam bending theory and assuming that bone has a linear elastic behavior, the quantities of ultimate bending strength, Young's modulus and fracture strain, was determined respectively from following equations:

$$
\begin{aligned}
& \sigma=\frac{F L C}{4 I} \\
& E=\frac{F^{3}}{48 I \delta}
\end{aligned}
$$

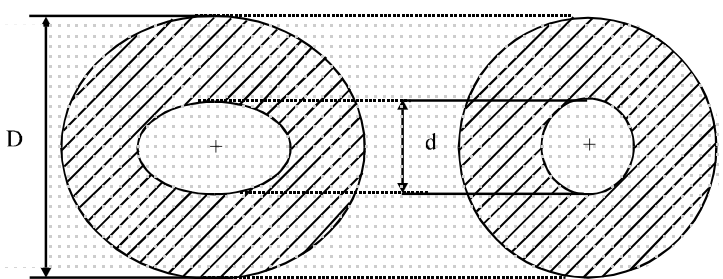

Fig. 4: Elliptical and circular cross-sections for models

$$
\varepsilon=\delta\left(\frac{12 \mathrm{C}}{\mathrm{L}^{2}}\right)
$$

where, $\mathrm{F}$ is the fracture force, $\delta$ is the deformation at the fracture instant, $\mathrm{L}$ is the active length of bone shaft (fulcra span length) and $\mathrm{C}$ is half of the small outer diameter of the cross-section (D/2), at load applying point (midsection of bone shaft). Area moment of inertia for the hollow elliptical cross-section was calculated using following equation (Fig. 4):

$$
\mathrm{I}=\frac{\pi}{64}\left[\left(\mathrm{~B} \cdot \mathrm{D}^{3}\right)-\left(\mathrm{b} \cdot \mathrm{d}^{3}\right)\right]
$$

In bending test, intrinsic stiffness is equal to Young's modulus (E), which is the slope of the straight line portion of the stress-strain diagram. Flexural rigidity is equal to $\mathrm{EI}$ and extrinsic stiffness is calculated from the term $48 \mathrm{EI} \mathrm{L}^{-3}$. Fracture energy is the area under force-deformation curve, up to the point of fracture ${ }^{[1,8,10]}$.

Finite element modeling and analysis: After evaluation and classification of mechanical properties, modeling of the specimens was made by ANSYS software. In first step, geometric dimensions of the models were defined accordingly by the measured dimensions of each specimen and the variations of these dimensions along the specimens' length were disregarded. It means that the shaft was considered as a uniform elliptical cylinder, which had interesting results albeit varying cross-section dimensions along the bone shaft, which is mentioned ahead. In second step, the bone cross-section was supposed to be circular along its shaft. The idea was made to consider the effect of area moment of inertia on bone strength in bending while keeping the effective diameters fixed. Thus, bone shaft was modeled as a circular cylinder. Inner and outer diameters of the circular model were the same as smaller diameters which were directly measured in specimens (D, d). Thus, cross-section area of circular model was smaller than that of elliptical model. 
Linear elastic and isotropic properties were considered for the models. Each model was meshed by 3-D, hexagonal and eight-node elements and same Poisson's ratio $v=0.3$ ) was determined for them ${ }^{[10,13,14]}$. Young's modulus calculated from test results was appointed to each model. Providing simple support boundary conditions at two ends of the shaft of each model, fracture force was applied to the upper surface nodes of midsection upper elements (Fig. 5).

While performing tests, load application was not enabled as an ideal point-force. Therefore, load application to the model was distributed as several point-forces on above-mentioned elements nodes.

\section{RESULTS AND DISCUSSION}

Using force-deformation curves, quantities of fracture force and deformation, fracture bending moment, fracture energy and extrinsic stiffness were evaluated for all specimens. Several quantities, obtained from wet tests, were plotted versus each other. Some of these plots which demonstrate the relations between different parameters are shown in Fig. 6-10.

In spite of few numbers, dry bone specimens showed significant differences in some characteristics from wet specimens. Results show an increase of about $44 \%$ in Young's modulus, as well as about $14 \%$ in bending strength for dry bone. However, toughness modulus and fracture strain decrease about 11 and 32\% respectively after drying. In Table 1 , average values of studied groups for wet and dry tests are presented.

After finite element modeling and analysis, deformations and maximum (tensile) stresses which were evaluated from nodal and element solutions, were compared with experimental results. There are interesting proximities of maximum (tensile) stresses in elliptical models to experimental fracture strength of bone specimens. Noticing Table 2, the average difference between experimental ultimate (fracture)

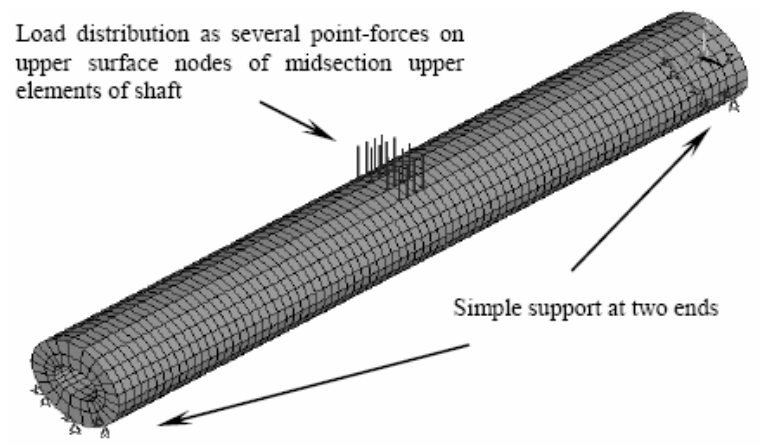

Fig. 5: Simple 3-D element model of tibia shaft in three-point bending

Table 1: Statistical results for the specimens

\begin{tabular}{|c|c|c|c|c|}
\hline \multirow[b]{2}{*}{ Quantity } & \multicolumn{2}{|c|}{ Wet Bone $(\mathrm{N}=10)$} & \multicolumn{2}{|c|}{ Dry Bone $(\mathrm{N}=2)$} \\
\hline & Ave. & $\mathrm{SD}$ & Ave. & \\
\hline Area moment of inertia $\left(\mathrm{mm}^{4}\right)$ & 1472.8000 & 310.5000 & 1643.3000 & \pm 200.1000 \\
\hline Mid-shaft cross-section area $\left(\mathrm{mm}^{2}\right)$ & 118.6700 & 16.0300 & 116.9100 & \pm 11.1500 \\
\hline Bone shaft active length $(\mathrm{mm})$ & 106.0000 & 5.1000 & 116.5000 & \pm 8.5000 \\
\hline Fracture energy $(\mathrm{J})$ & 4.7300 & 1.1000 & 6.0100 & \pm 0.2200 \\
\hline Fracture bending moment (N.m) & 40.9200 & 6.7800 & 50.8400 & \pm 4.7300 \\
\hline Elastic (Young's) modulus (GPa) & 6.5800 & 0.9300 & 9.4700 & \pm 1.0600 \\
\hline Toughness modulus (MPa) & 3.7700 & 0.9000 & 3.3400 & \pm 0.5100 \\
\hline Ultimate (Fracture) strength (MPa) & 177.8800 & 9.2300 & 202.5400 & \pm 2.4300 \\
\hline Extrinsic stiffness $\left(\mathrm{kN} \mathrm{mm}^{-1}\right)$ & 0.3860 & 0.0660 & 0.4720 & \pm 0.0110 \\
\hline Fracture strain & 0.0394 & 0.0056 & 0.0267 & \pm 0.0009 \\
\hline Fracture load (kN) & 1.5470 & 0.2440 & 1.7590 & \pm 0.0480 \\
\hline Deformation (mm) & 5.7500 & 0.5600 & 5.0300 & \pm 0.0900 \\
\hline
\end{tabular}

Table 2: Experimental results and comparable results evaluated from finite element modeling

\begin{tabular}{|c|c|c|c|c|c|c|c|c|c|}
\hline \multirow[b]{2}{*}{$\begin{array}{l}\text { Fracture } \\
\text { load } \\
(\mathrm{kN})\end{array}$} & \multirow[b]{2}{*}{$\begin{array}{l}\text { Young's } \\
\text { modulus } \\
\text { (GPa) }\end{array}$} & \multirow[b]{2}{*}{$\begin{array}{l}\text { Experimental } \\
\text { deformation } \\
(\mathrm{mm})\end{array}$} & \multirow[b]{2}{*}{$\begin{array}{l}\text { Fracture } \\
\text { strength } \\
\text { (MPa) }\end{array}$} & \multirow{2}{*}{$\begin{array}{l}\text { Elliptical } \\
\text { model } \\
\text { deformation } \\
(\mathrm{mm})\end{array}$} & \multicolumn{2}{|c|}{$\begin{array}{l}\text { Maximum stress in } \\
\text { elliptical model (MPa) }\end{array}$} & \multirow{2}{*}{$\begin{array}{l}\text { Circular } \\
\text { model } \\
\text { deformation } \\
(\mathrm{mm})\end{array}$} & \multicolumn{2}{|c|}{$\begin{array}{l}\text { Maximum stress in } \\
\text { circular model (MPa) }\end{array}$} \\
\hline & & & & & $\begin{array}{l}\text { Nodal } \\
\text { solution }\end{array}$ & $\begin{array}{l}\text { Element } \\
\text { solution }\end{array}$ & & $\begin{array}{l}\text { Nodal } \\
\text { solution }\end{array}$ & $\begin{array}{l}\text { Element } \\
\text { solution }\end{array}$ \\
\hline $\begin{array}{l}\text { Wet tests } \\
1.547\end{array}$ & 6.58 & 5.75 & 177.88 & 4.67 & 178.47 & 180.16 & 5.29 & 205.76 & 207.60 \\
\hline $\begin{array}{l}\text { Dry tests } \\
1.759\end{array}$ & 9.47 & 5.03 & 202.54 & 4.18 & 204.13 & 205.07 & 4.51 & 227.66 & 228.56 \\
\hline
\end{tabular}


Am. J. Applied Sci., 6 (3): 463-470, 2009

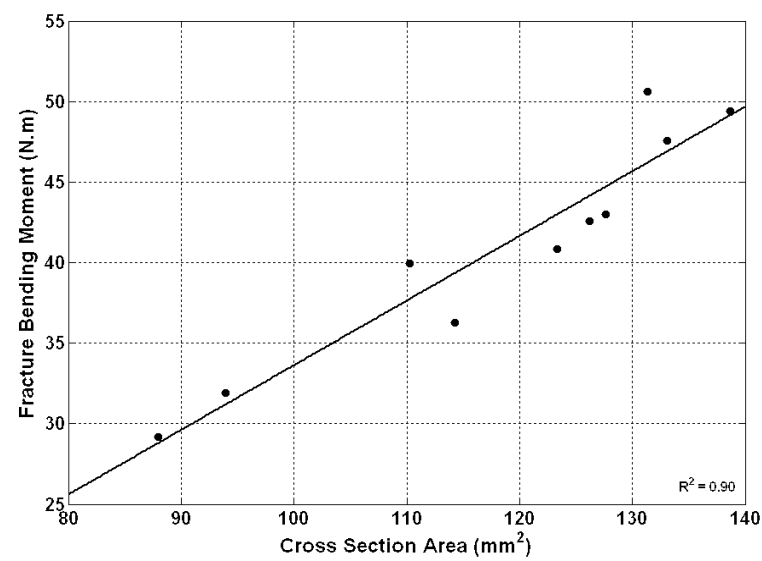

Fig. 6: Fracture bending moment-cross-section area diagram, $\mathrm{R}^{2}=0.90$

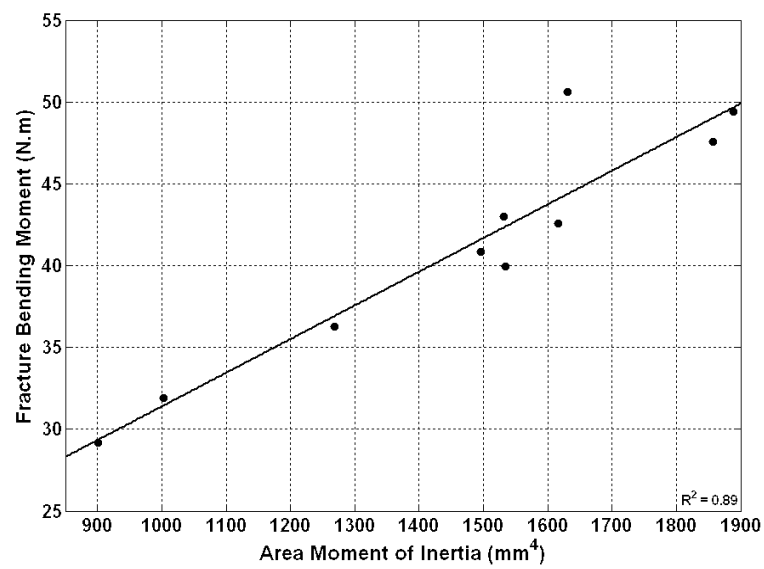

Fig. 7: Fracture bending momentarea moment of inertia diagram, $\mathrm{R}^{2}=0.89$

strength and maximum (tensile) stress occurred in elliptical models is acceptably about less than $2 \%$ for wet specimens and about $1 \%$ for dry specimens. Circular models in same loading conditions show about $16 \%$ increase in maximum (tensile) stress for wet specimens, while the value for dry specimens is about less than $13 \%$. It should be considered that circular model results were compared with test results assuming elliptical cross-section for test specimens rather than circular cross-section. i.e., no calculation from test data was performed assuming circular cross-section for the specimens because of obvious deviation in cross-section of bone shafts from circular geometry (Fig. 2).

Since, in all specimens, the support length to bone small outer diameter ratio (L/D) was greater than 10 , transverse shear stress in the shaft cross-

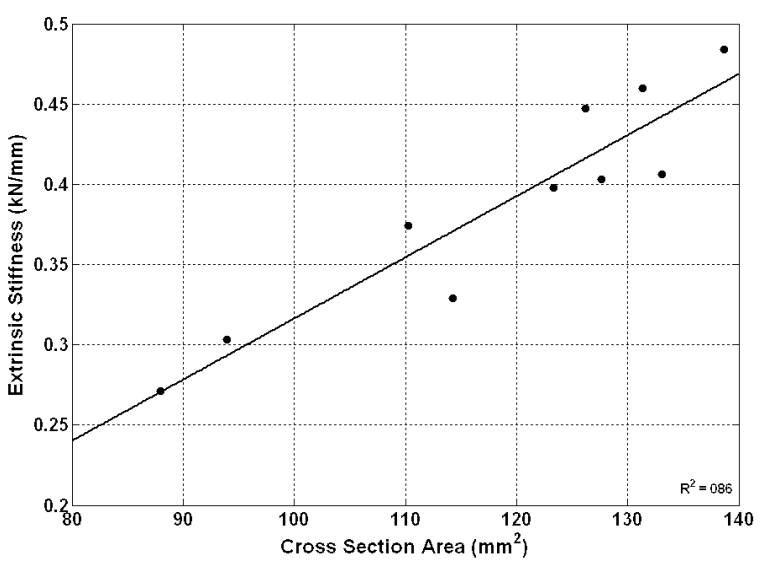

Fig. 8: Extrinsic stiffness-cross-section area diagram, $\mathrm{R}^{2}=0.86$

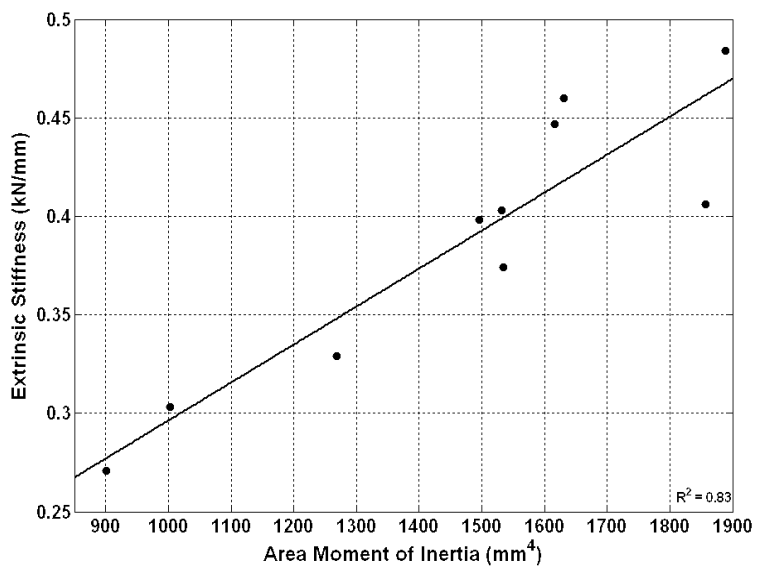

Fig. 9: Extrinsic stiffness-area moment of inertia diagram, $\mathrm{R}^{2}=0.83$

section could be disregarded and the loading could be assumed to be pure bending.

Presented ultimate strength is the bone flexural strength and compressive, tensile or shear strengths could not be obtained using bending test.

Fracture strain was averagely under $4 \%$. In addition, failure firstly began in lower side of bone shaft. i.e., tensile failure occurred before compressive failure (Fig. 3). These show the quasi-brittle behavior of bone.

Bone extrinsic stiffness depends on its geometry. It is equal to the slope of straight line portion of force-deformation curve. Using stress-strain diagram, the slope of the straight line portion represents the intrinsic stiffness or Young's modulus. Here, the assumption of linear elastic behavior accompanied with determining the Young's modulus directly from 
Am. J. Applied Sci., 6 (3): 463-470, 2009

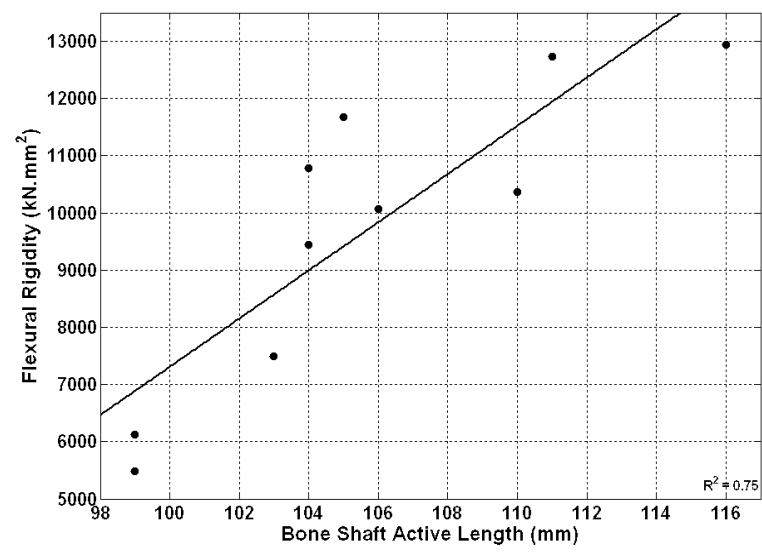

Fig. 10: Flexural rigidity-bone shaft active length diagram, $R^{2}=0.75$

slope of the straight portion of stress-strain curves rather than the formula in Eq. 2.

Values of Young's modulus are reported in a wide range of 1-30 $\mathrm{GPa}$ in different studies, depending on animal, specimen type (cortical or spongy), test method and etc. Although a disadvantage of three-point bending test is the local deformation of the bone at the point where the force is applied, resulting in an underestimation of the Young's modulus ${ }^{[15]}$, the values for cortical bone of sheep in bending presented here, seem to be close to reports $^{[8,10]}$.

As mentioned before, fracture energy is equal to the area under force-deformation curve, up to the point of fracture. However, toughness modulus is evaluated from the area under stress-strain diagram.

According to Fig. 6-10, the correlations showed that fracture bending moment had proximate relations with bone cross-section area and area moment of inertia. (With 95\% confidence bounds) Extrinsic stiffness had also significant relations with bone cross-section area and area moment of inertia. However, the quantities of ultimate strength and fracture energy did not have such significant relations with geometric parameters, i.e., cross-section area, area moment of inertia and active length of bone shaft.

Dry bone test can not bear acceptable results as considering a living tissue. But here, this test is performed for providing a comparison. After it is dried, bone's Young's modulus and strength will generally increase, but its toughness will decrease. Decreased toughness is due to the fact that dry bone is more brittle than wet bone, so while the stress must be greater to cause it to fracture, it actually absorbs

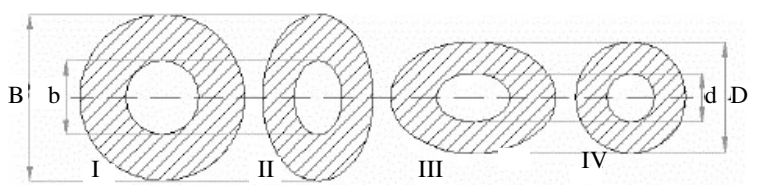

Fig. 11: Possible approximations for bone shaft cross-section

less energy prior to failure ${ }^{[8]}$. Decreased fracture strain is also due to increase in brittleness of dry bone.

Elliptical cross-section of the bone shaft enhances its strength upon bending moments in sagittal plane -the plane made by larger diameter of cross-section and neutral axis of the shaft- by decreasing bending stresses. It is obvious that maximum area moment of inertia occurs in coronal plane for tibiae shaft. However, assuming circular cross-section with the smaller diameters for bone shaft, increases bending stresses due to decrease in area moment of inertia ${ }^{[16]}$. According to Fig. 11, area moment of inertia for different cross-sections could be compared as:

$$
\mathrm{I}_{\mathrm{I}}>\mathrm{I}_{\mathrm{II}}>\mathrm{I}_{\mathrm{III}}>\mathrm{I}_{\mathrm{IV}}
$$

where, $\mathrm{I}_{\mathrm{I}}, \mathrm{I}_{\mathrm{II}}, \mathrm{I}_{\mathrm{III}}$ and $\mathrm{I}_{\mathrm{IV}}$ are area moment of inertia for circular cross-section with the larger diameters, elliptical cross-section in coronal plane, elliptical cross section in sagittal plane and circular crosssection with the smaller diameters respectively.

If the model was assumed to have a circular cross-section with same value of area as in elliptical cross-section (fixed area), it would result in an increase in area moment of inertia and a decrease in maximum bending stress. The value of area moment of inertia for fixed area circular cross-section would be the average of $\mathrm{I}_{\mathrm{II}}$ and $\mathrm{I}_{\mathrm{III}}$. Thus, it could decrease the maximum stress about $16 \%$ for wet specimens.

In some studies, the definition of cross-section area moment of inertia has been based on the elliptic approximation of the cortical bone cross-section. However, this has been shown to result in significant errors $^{[9,16]}$. There is a measurement system, called Peripheral Quantitative Computed Tomography. Cross-section area moment of inertia calculated by the PQCT system, even with the restricted reproducibility with small specimens, gives an alternative tool for the calculation of stress and elastic modulus, not only in bending studies but also in experiments employing torque testing. Still, after accurate definition of the bone cross-section at mid- 


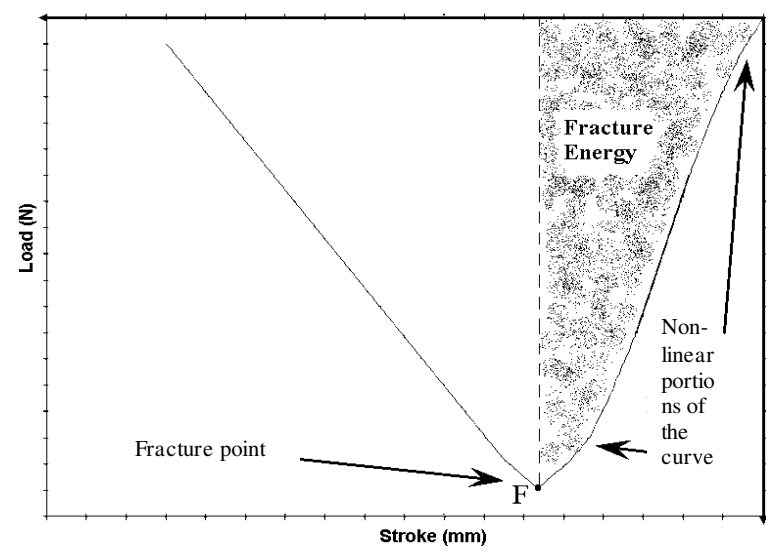

Fig. 12: Force-deformation curve for a specimen tested in three-point bending

shaft, residual errors exist in differentiating geometric and material changes in whole bone tests ${ }^{[9]}$.

In this study, geometric irregularities and variations of bone shaft cross-section dimensions were disregarded. Thus, the cross-section was considered symmetric and neutral axis was assumed to pass the center of cross-section of the shaft and only midsection dimensions were measured. However, proximity of experimental to (first) model results of maximum (tensile) stresses may validate these assumptions. Therefore, it might be useful to consider the shaft as a uniform elliptical cylinder and sufficient to know the geometric dimensions of midcross-section which is the critical cross-section of the shaft in three-point bending, to analyze bending in long bone shaft.

It should be reminded that finite element modeling and analysis was done with the assumption of linear elastic behavior of bone and the differences between experimental and model deformations were due to the difference between bone actual behavior and above-mentioned assumption. Thus, experimental deformations were larger than model deformations (Fig. 12).

\section{CONCLUSION}

In this study, the intention was to consider mechanical properties of whole bone as a crucial tissue in living system and the effects of whole bone geometry on its mechanical properties, which can not be accomplished for machined bone specimens. Thus, an idea was presented to test long bones in three-point bending and the action was done according to standard protocols for both wet and dry specimens.
In this research, it was shown that the whole bone shaft bending strength did not have effective relations with the variations of cross-section geometric dimensions along the bone length relative to midsection while the whole bone was straight and its lateral curvature could be slighted and modeling could be done while disregarding these variations. Also, the role of elliptical cross-section rather than assumed circular cross-section was shown to enhance bending strength of bone shaft by reducing stresses due to an increase in area moment of inertia.

\section{REFERENCES}

1. An, Y.H. and R.A. Draughn, (Ed.), 1999. Mechanical Testing of Bone and The BoneImplant Interface, CRC Press, Boca Raton, FL.

2. Sadeghi Mehr, M., F .Hosseini Mansoub, K. HosseinPour, Feb. 2007. The effect of density on fracture toughness of bovine cortical bone by four point bending method. Proceedings of $13^{\text {th }}$ Iranian Conference on Biomedical Engineering, Tehran, Iran, 596-601.

3. Liu, D., H.D. Wagner and S. Weiner, 2000. Bending and fracture of compact circumferential and osteonal lamellar bone of the baboon tibia. J. Mater. Sci. Mater. Med., 11: 49-60.

4. Liu, D., S. Weiner and H.D. Wagner, 1999. Anisotropic mechanical properties of lamellar bone using miniature cantilever bending specimens. J. Biomech., 32: 647-654.

5. Cowin, S.C., 1981. Mechanical Properties of Bone. ASME, New York.

6. Van Der Meulen, M.C.H., K.J. Jepsen and B. Mikic, 2001, Understanding bone strength: Size Isn't everything. Bone, 29: 101-104.

7. Azghani, M., M. SadeghiMehr, A. YavariKia and R. Rahimian, Nov. 2005. Consideration of mechanical properties of sheep metacarpals in pure torsion. Proceedings of $13^{\text {th }}$ Iranian Conference on Biomedical Engineering, Tabriz, Iran, 596-601.

8. Turner, C.H. and D.B. Burr, 1993. Basic biomechanical measurements of bone. Bone, 14: 595-608.

9. Jamsa, T., P. Jalovaara, Z. Peng, H.K. Vaananen and J. Tuukkanen, 1998, Comparison of threepoint bending test and peripheral quantitative computed tomography analysis in the evaluation of the strength of mouse femur and tibia. Bone, 23: $155-161$. 
Am. J. Applied Sci., 6 (3): 463-470, 2009

10. Cowin, S.C., 2001. Bone Mechanics Handbook. $2^{\text {nd }}$ Edn., CRC Press, Boca Raton.

11. Newman, E., A.S. Turner and J.D. Wark, 1995. The potential of sheep for the study of osteopenia: Current status and comparison with other animal models. Bone, 16: 277-284.

12. Zioupos, P., J.D. Currey and A. Casinos, 2001. Tensile fatigue in bone: Are cycles, or time to failure, or both, important? J. Theor. Biol., 210: 389-399.

13. Raeisi Najafi, A., A.R. Arshi, M.R. Eslami, S. Fariborz and M. Moeinzadeh, 2007. Haversian cortical bone model with many radial microcracks: An elastic analytic solution, Med. Eng. Phys., 29: 708-717.
14. Raeisi Najafi, A., A.R. Arshi, M.R. Eslami, S. Fariborz and M. Moeinzadeh, 2007. Micromechanics fracture in osteonal cortical bone: A study of the interactions between microcrack propagation, microstructure and the material properties. J. Biomech., 40: 2788-2795.

15. Turner, C.H., 1993. Measurement of Young's modulus in bending tests can be highly inaccurate. J. Bone Joint Surg., 11: 462-463.

16. Lieberman, D.E., J.D. Polk and B. Demes, 2004. Predicting long bone loading from crosssectional geometry. Am. J. Phys. Anthropol., 123: $156-171$. 